\title{
Evaluation of Eeg Pattern and Seizure Types of Genetic Dysmorphic Syndromes: Report of 50 Patients and Review of the Literature
}

\author{
Gürkan Gürbüz $^{1, ~ *}$, Filiz Hazan², Selvinaz Edizer ${ }^{1}$, Bahar Toklu Baysal ${ }^{1}$, Ünsal Yilmaz ${ }^{1}$, \\ Aycan Ünalp ${ }^{1}$ \\ ${ }^{1}$ Dr. Behçet Uz Children's Hospital, Department of Pediatric Neurology, University of Health Sciences, Izmir, Turkey \\ ${ }^{2}$ Dr. Behçet Uz Children's Hospital, Department of Medical Genetics, University of Health Sciences, Izmir, Turkey
}

Email address:

drgurkangurbuz@ hotmail.com(G. Gürbüz)

${ }^{*}$ Corresponding author

\section{To cite this article:}

Gürkan Gürbüz, Filiz Hazan, Selvinaz Edizer, Bahar Toklu Baysal, Ünsal Yilmaz, Aycan Ünalp. Evaluation of Eeg Pattern and Seizure Types of Genetic Dysmorphic Syndromes: Report of 50 Patients and Review of the Literature. American Journal of Internal Medicine.

Vol. 6, No. 5, 2018, pp. 86-93. doi: 10.11648/j.ajim.20180605.11

Received: July 8, 2018; Accepted: July 23, 2018; Published: August 20, 2018

\begin{abstract}
Many chromosomal anomalies manifest with epilepsy. Only few typical EEG and seizure type have been identified in genetic syndromes. Identification of typical seizure and EEG findings of certain genetic syndromes may serve as a guide for genetic analysis. This study aims to find typical EEG paterns of spesific genetic syndromes. The study enrolled 50 patients aged 0-16 years with a diagnosis of epilepsy and genetic syndrome in between 2014-2017 at the Dr. Behçet UZ Children's Hospital Pediatric Neurology and Medical Genetics departments. Patients' characteristics and dysmorphic features were retrieved from Medical Genetic outpatient clinic patient files, while seizure type, epileptic syndromic classification, EEG and brain MRI findings, age at onset and frequency of seizure were determined from pediatric neurology follow-ups. Fifty patients (29 girls) with a mean age of $6.52 \pm 3.67$ years $(\max =16, \min =1)$ were enrolled. Twenty-two patients had microdeletion-duplication (44\%), 12 had chromosomal anomalies (24\%) and 16 had monogenic syndrome (32\%). Pathology was present in the EEGs of 40 patients $(80 \%)$. Focal epileptic disorder was determined in 28 subjects (56\%), epileptic encephalopathy in $7(14 \%)$, and generalized epileptic disorder in $5(10 \%)$ Identification of seizure type and EEG pattern specific to each genetic dysmorphic syndrome may give clues to clinicians in recognizing these syndromes. However, in order to detect other specific EEG patterns, there is a need for multicentre studies with more patients.
\end{abstract}

Keywords: Epilepsy, Electroencephalography, Genetic Syndrome

\section{Introduction}

Many chromosomal anomalies are manifested by neurological findings such as central nervous system structural disorders, epilepsy, neuromotor developmental retardation as well as dysmorphic findings. While epilepsy and electroencephalogram (EEG) findings are well defined in rare genetic syndromes such as Angelman syndrome and Rett syndrome, typical EEG and seizure characteristics have not been identified in most other genetic syndromes. This limitation arises from the fact that the number of patients is insufficient and the number of studies conducted in this direction is inadequate.

Since the proportion of consanguineous marriages, birth rate and young population rates are higher in Turkey than developed countries such as Europe and United States of America, the ratio of the cases with genetic dysmorphic syndrome is also relatively higher. Despite this high level, the number of genetic laboratories in our country is inadequate and the diagnosis of syndromes is often made with clues of clinical and laboratory methods. For this reason, it is thought that the identification of typical seizure and EEG findings of certain genetic syndromes may be a guide for genetic analysis. 


\section{Methods}

The study included 50 patients aged between $0-16$ years followed up between the years 2014 and 2017 with the diagnosis of epilepsy and genetic syndrome in Dr. Behçet UZ Children's Hospital Pediatric neurology and Medical Genetics departments. Ethical Committee approval was obtained from our tertiary hospital (protocol no:2016/108), and the study was executed while abiding by the Declaration of Helsinki. Written informed consent was obtained from all subjects. While the patients' characteristics and dysmorphic features were obtained from Medical Genetic outpatient clinic patient files; seizure type, epileptic syndromic classification, EEG and brain MR findings, age and frequency of seizure onset were aquired from pediatric neurology follow-up files.

Genetic syndromes were evaluated in 3 main groups as chromosomal anomalies, microdeletion syndromes and monogenic syndromes. The clinical diagnoses of all patients were confirmed by cytogenetic or molecular genetic analyses including standard karyotypes, cytogenetic-molecular studies (FISH) or molecular studies (methylation tests, array-CGH, sequence anaysis). Patients diagnosed by only clinical criteria were excluded.

Patients who had at least one epileptic seizure were included in the study. Classification of seizures was done in line with the recommendation of ILEA. Electroencephalograms of patients with seizures were drawn according to the international 10-20 system in the neuropsychological unit of our hospital and evaluated by our pediatric neurology specialists. EEG results were evaluated in 4 groups as 1Normal, 2-Focal epileptic disorder, 3-Generalized epileptic disorder and 4-Epileptic encephalopathy.

Brain magnetic resonance investigation (MRI) imaging (1.5 Tesla) was performed at least once in all patients and all MRs were evaluated by competent radiologists. MR findings were examined in 3 groups as 1-Normal, 2- Sequel cerebral lesions, 3- Structural cerebral lesions.

Cognitive assessment of the patients was performed by WISC-R tests, which were conducted by psychologists of our hospital.

\section{Results}

Distribution of genetic syndromes and their demographic features are shown in Table 1 and 2. The mean age of the patients was determined as $6.52 \pm 3.67$ years $(\max =16$, $\min$ $=1)$ in this study involving a total of 50 patients ( 29 girls). Mean age was $4.83 \pm 2.55$ years $(\max =9, \min =1)$ in chromosomal disorders, $6.14 \pm 3,38$ years $(\max =14$, $\min =$ 1) in patients with microdeletion-duplication syndrome, $6,52 \pm 3,67(\max =16, \min =1)$ in monogenic syndromes, respectively $(\mathrm{p}=0.034)$.

Table 1. Genetic Dysmorphic Syndromes.

\begin{tabular}{l} 
Microdeletion-duplication $(n=22)$ \\
Prader willi $(\mathrm{n}=5)$ \\
Angelman $(\mathrm{n}=4)$ \\
Wolf Hirschhorn $(\mathrm{n}=3)$ \\
Williams $(\mathrm{n}=3)$ \\
Cri du chat $(\mathrm{n}=2)$ \\
$1 \mathrm{p} 36$ del $(\mathrm{n}=2)$ \\
Potock1 $(\mathrm{n}=1)$ \\
Miller Diecker $(\mathrm{n}=1)$ \\
22q dup $(\mathrm{n}=1)$ \\
Chromosomal $(\mathrm{n}=12)$ \\
Down $(\mathrm{n}=7)$ \\
Patau $(\mathrm{n}=2)$ \\
Ring $20(\mathrm{n}=1)$ \\
$18 \mathrm{q}$ del $(\mathrm{n}=1)$ \\
Klinifelter $(\mathrm{n}=1)$ \\
Monogenic $(n=16)$ \\
Rett $(\mathrm{n}=7)$ \\
Kabuki make-up $(\mathrm{n}=3)$ \\
Apert $(\mathrm{n}=2)$ \\
Saethre $(\mathrm{n}=1)$ \\
Bardet biedl $(\mathrm{n}=1)$ \\
Noonan $(\mathrm{n}=1)$ \\
Triple A $(\mathrm{n}=1)$ \\
\hline
\end{tabular}

Table 2. EEG Disorders and Genetic Syndromes.

\begin{tabular}{|c|c|c|c|c|c|c|c|c|c|c|c|c|c|}
\hline & \multirow{2}{*}{\multicolumn{3}{|c|}{ Chromosomal }} & \multicolumn{6}{|l|}{ Mutation } & \multirow{2}{*}{\multicolumn{3}{|c|}{ - Total }} & \multirow{3}{*}{$\begin{array}{l}\text { P } \\
\text { Value }\end{array}$} \\
\hline & & & & \multicolumn{3}{|c|}{ Microdeletion duplication } & \multicolumn{3}{|l|}{ Monogenic } & & & & \\
\hline & Mean \pm SD & Max. & Min. & Mean \pm SD & Max. & Min. & Mean \pm SD & Max. & Min. & $\operatorname{Mean} \pm$ SD & Max. & Min. & \\
\hline Age & $4.83 \pm 2.55$ & 9 & 1 & $6.14 \pm 3,38$ & 14 & 1 & $8.31 \pm 4.16$ & 16 & 2 & $6.52 \pm 3.67$ & 16 & & 0.034 \\
\hline & Median & Max. & Min. & Median & Max. & Min. & Median & Max. & Min. & Median & Max. & Min. & \\
\hline $\begin{array}{l}\text { First seizure age } \\
\text { (month) }\end{array}$ & 15 & 96 & 1 & 21 & 84 & 1 & 30 & 96 & 1 & 21 & 96 & 1 & 0.361 \\
\hline & $\mathrm{n}$ & Row $\%$ & $\begin{array}{l}\text { Column } \\
\%\end{array}$ & $\mathrm{n}$ & Row $\%$ & $\begin{array}{l}\text { Column } \\
\%\end{array}$ & $\mathrm{n}$ & Row $\%$ & $\begin{array}{l}\text { Column } \\
\%\end{array}$ & $\mathrm{n}$ & Row $\%$ & $\begin{array}{l}\text { Column } \\
\%\end{array}$ & \\
\hline Gender & & & & & & & & & & & & & \\
\hline Female & 5 & $17.2 \%$ & $41.7 \%$ & 12 & $41.4 \%$ & $54.5 \%$ & 12 & $41.4 \%$ & $75.0 \%$ & 29 & $100 \%$ & $58.0 \%$ & 0.220 \\
\hline $\begin{array}{l}\text { Male } \\
\text { WISR-C }\end{array}$ & 7 & $33.3 \%$ & $58.3 \%$ & 10 & $47.6 \%$ & $45.5 \%$ & 4 & $19.0 \%$ & $25.0 \%$ & 21 & $100 \%$ & $42.0 \%$ & \\
\hline Mild MR & 0 & $0 \%$ & $0 \%$ & 1 & $16.7 \%$ & $7.7 \%$ & 5 & $83.3 \%$ & $45.5 \%$ & 6 & $100 \%$ & $20.0 \%$ & 0.032 \\
\hline Moderate MR & 1 & $12.5 \%$ & $16.7 \%$ & 6 & $75.0 \%$ & $46.2 \%$ & 1 & $12.5 \%$ & $9.1 \%$ & 8 & $100 \%$ & $26.7 \%$ & \\
\hline $\begin{array}{l}\text { Severe MR } \\
\text { EEG } \\
\text { Background }\end{array}$ & 5 & $31.3 \%$ & $83.3 \%$ & 6 & $37.5 \%$ & $46.2 \%$ & 5 & $31.3 \%$ & $45.5 \%$ & 16 & $100 \%$ & $53.3 \%$ & \\
\hline $\begin{array}{l}\text { Background } \\
\text { Disorganized }\end{array}$ & 3 & $16.7 \%$ & $25.0 \%$ & 8 & $44.4 \%$ & $36.4 \%$ & 7 & $38.9 \%$ & $43.8 \%$ & 18 & $100 \%$ & $36.0 \%$ & 0.645 \\
\hline
\end{tabular}




\begin{tabular}{|c|c|c|c|c|c|c|c|c|c|c|c|c|c|}
\hline & \multirow{2}{*}{\multicolumn{3}{|c|}{ Chromosomal }} & \multicolumn{6}{|l|}{ Mutation } & \multirow{2}{*}{\multicolumn{3}{|c|}{ Total }} & \multirow{3}{*}{$\begin{array}{l}P \\
\text { Value }\end{array}$} \\
\hline & & & & \multicolumn{3}{|c|}{ Microdeletion duplication } & \multicolumn{3}{|l|}{ Monogenic } & & & & \\
\hline & $\operatorname{Mean} \pm$ SD & Max. & Min. & Mean \pm SD & Max. & Min. & $\operatorname{Mean} \pm$ SD & Max. & Min. & Mean \pm SD & Max. & Min. & \\
\hline $\begin{array}{l}\text { Normal } \\
\text { EEG Pathology }\end{array}$ & 9 & $28,1 \%$ & $75,0 \%$ & 14 & $43.8 \%$ & $63.6 \%$ & 9 & $28.1 \%$ & $56.3 \%$ & 32 & $100 \%$ & $64.0 \%$ & \\
\hline Normal & 1 & $10.0 \%$ & $8.3 \%$ & 8 & $80.0 \%$ & $36.4 \%$ & 1 & $10.0 \%$ & $6.3 \%$ & 10 & $100 \%$ & $20.0 \%$ & 0.196 \\
\hline Focal & 9 & $32.1 \%$ & $75.0 \%$ & 8 & $28.6 \%$ & $36.4 \%$ & 11 & $39.3 \%$ & $68.8 \%$ & 28 & $100 \%$ & $56.0 \%$ & \\
\hline Generalized & 1 & $20.0 \%$ & $8.3 \%$ & 2 & $40.0 \%$ & $9.1 \%$ & 2 & $40.0 \%$ & $12.5 \%$ & 5 & $100 \%$ & $10.0 \%$ & \\
\hline $\begin{array}{l}\text { Encephalopathy } \\
\text { EEG Pathology }\end{array}$ & 1 & $14.3 \%$ & $8.3 \%$ & 4 & $57.1 \%$ & $18.2 \%$ & 2 & $28.6 \%$ & $12.5 \%$ & 7 & $100 \%$ & $14.0 \%$ & \\
\hline Absent & 1 & $10.0 \%$ & $8.3 \%$ & 8 & $80.0 \%$ & $36.4 \%$ & 1 & $10.0 \%$ & $6.3 \%$ & 10 & $100 \%$ & $20.0 \%$ & 0.035 \\
\hline $\begin{array}{l}\text { Present } \\
\text { MR Pathology }\end{array}$ & 11 & $27.5 \%$ & $91.7 \%$ & 14 & $35.0 \%$ & $63.6 \%$ & 15 & $37.5 \%$ & $93.8 \%$ & 40 & $100 \%$ & $80.0 \%$ & \\
\hline Absent & 5 & $14.3 \%$ & $41.7 \%$ & 16 & $45.7 \%$ & $72.7 \%$ & 14 & $40.0 \%$ & $87.5 \%$ & 35 & $100 \%$ & $70.0 \%$ & 0.042 \\
\hline $\begin{array}{l}\text { Present } \\
\text { AED Response }\end{array}$ & 7 & $46.7 \%$ & $58.3 \%$ & 6 & $40.0 \%$ & $27.3 \%$ & 2 & $13.3 \%$ & $12.5 \%$ & 15 & $100 \%$ & $30.0 \%$ & \\
\hline Complete & 10 & $27.8 \%$ & $83.3 \%$ & 16 & $44.4 \%$ & $72.7 \%$ & 10 & $27.8 \%$ & $62.5 \%$ & 36 & $100 \%$ & $72.0 \%$ & 0.308 \\
\hline Partial & 0 & $0.0 \%$ & $0.0 \%$ & 4 & $44.4 \%$ & $18.2 \%$ & 5 & $55.6 \%$ & $31.3 \%$ & 9 & $100 \%$ & $18.0 \%$ & \\
\hline No Response & 2 & $40.0 \%$ & $16.7 \%$ & 2 & $40.0 \%$ & $9.1 \%$ & 1 & $20.0 \%$ & $6.3 \%$ & 5 & $100 \%$ & $10.0 \%$ & \\
\hline
\end{tabular}

OneWay ANOVA Test - Post Hoc Test: Fisher's Least Significant Difference (LSD) / Kruskal Wallis Test (Monte Carlo) / Fisher Exact Test (Monte Carlo) / Pearson Chi Square Test (Monte Carlo)

Abbreviations: MR: Mental retardation AED: Antiepileptic drug.

22 patients had microdeletion-duplication (44\%), 12 patients had chromosomal anomalies (24\%) and 16 patients had monogenic syndrome (32\%). Genetic analyses of the parents of the patients with otosomal dominat and X linked inherited syndrome (Rett, Kabuki make up, Apert, Saethre, Bardet Biedl, Noonan) were normal. But the parents of the patients with otosomal recessive (Bardet Biedl and Triple A) inherited syndrome were carrier.

Pathology was present in the EEG of 40 patients (80\%). Focal epileptic disorder determined in $28(56 \%)$, epileptic encephalopathy in 7 (14\%), and generalized epileptic disorder in $5(10 \%)$.

While 11 of 12 patients with chromosomal anomalies and 15 of 16 patients with monogenic syndrome had pathologic EEG, only 14 of 22 patients with microdeletion-duplication syndrome had EEG abnormalities $(p=0.035)$.

All patients had brain MRI. While the MRI results of 35 $(70 \%)$ patients are normal, $15(30 \%)$ patients had structural and/or sequel lesions. Only 5 of the 15 patients determined pathology in MR had congenital structural cerebral lesions.

All of the patients were using at least 1 antiepileptic drug. While $36(72 \%)$ patients had complete response to antiepileptic drugs, 9 (18\%) patients had partial response. 5 $(10 \%)$ patients continued to have seizures unresponsive to antiepileptic drugs. Only 6 patients had epilepsy history in their first degree relatives.

\section{Discussion}

In the current literature, typical EEG findings and seizure patterns have been described in chromosomal anomalies such as Angelman syndrome, Rett syndrome, ring chromosome 20 $[1,2]$. No specific pattern was found in other, more rare syndromes.

Angelman and Prader willi syndrome (PWS) are caused by the lack of expression of parental genes (paternal in PWS and maternal in Angelman syndrome) on chromosome 15q11.2q13. The leading findings of Angelman syndrome are intelligence and developmental retardation, speech delay, epileptic seizures, epileptic encephalopathy, ataxic walking, spasticity, diffuse depigmentation and constantly smiling face expression. For this expression it is also called "Happy Puppet Syndrome" [3]. UBE3A mutation is positive. 80-90\% of patients have epilepsy and often begins at the first year of life. Atypical absence, myoclonic seizures are common. Nonconvulsive status epilepticus has also been reported [4].

Hyperkinetic stereotypes and behavioral disorders can lead to accidental seizures diagnosis and unnecessary drug use. Frontal dominant high wave bursts $(>200 \mathrm{mcV})$ at the frequency of 2-3c/s and high frequency spike and slow wave activities typical in the occipital region in EEG [5].

Mi Sun Yum et al. [6] found that the mean age of onset of seizure was 2 in their study with 18 Angelman cases. In these patients, it was reported that there was a statistically significant relationship between the ground rhythm disturbance and the seizure frequency, and it was found that these discharges were located in the frontal area as the age progressed parallel to the maturation changes in the EEG while the high amplitude sharp-spine slow waves dominated posteriorly at the beginning. Occipital discharges, notched delta waves, and high-amplitude teta-delta frequency waves in 4 Angelman syndrome patients in our study, manifested themselves with typical characteristics of age-appropriate EEG patterns as indicated in the literature as shown in Figure 1, 2, 3 and 4. The onset age of seizures was 20 months and only 1 patient had partial response to antiepileptic drugs, the other patients' seizures continued despite multiple antiepileptic treatments. Also in Angelman syndrome, autism spectrum disorders are seen frequently and seizures themselves contribute more to autism symptoms than expected from the underlying genetic pathology [7]. 


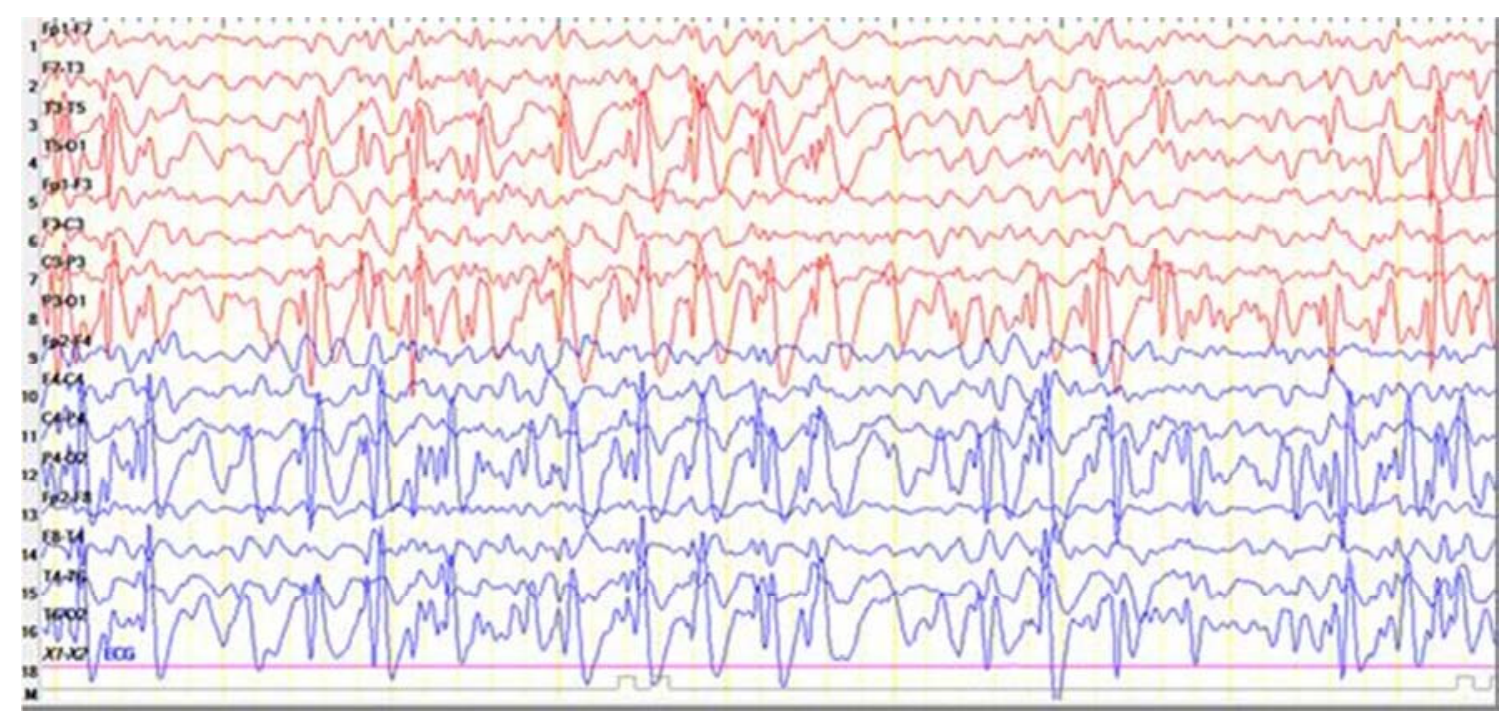

Figure 1. 6 year-old girl patient with Angelman syndrome. EEG shows occipital discharges.

(15)

Figure 2. 6 year-old girl patient with Angelman syndrome (Same patient above). Prominent teta-delta rhythm.

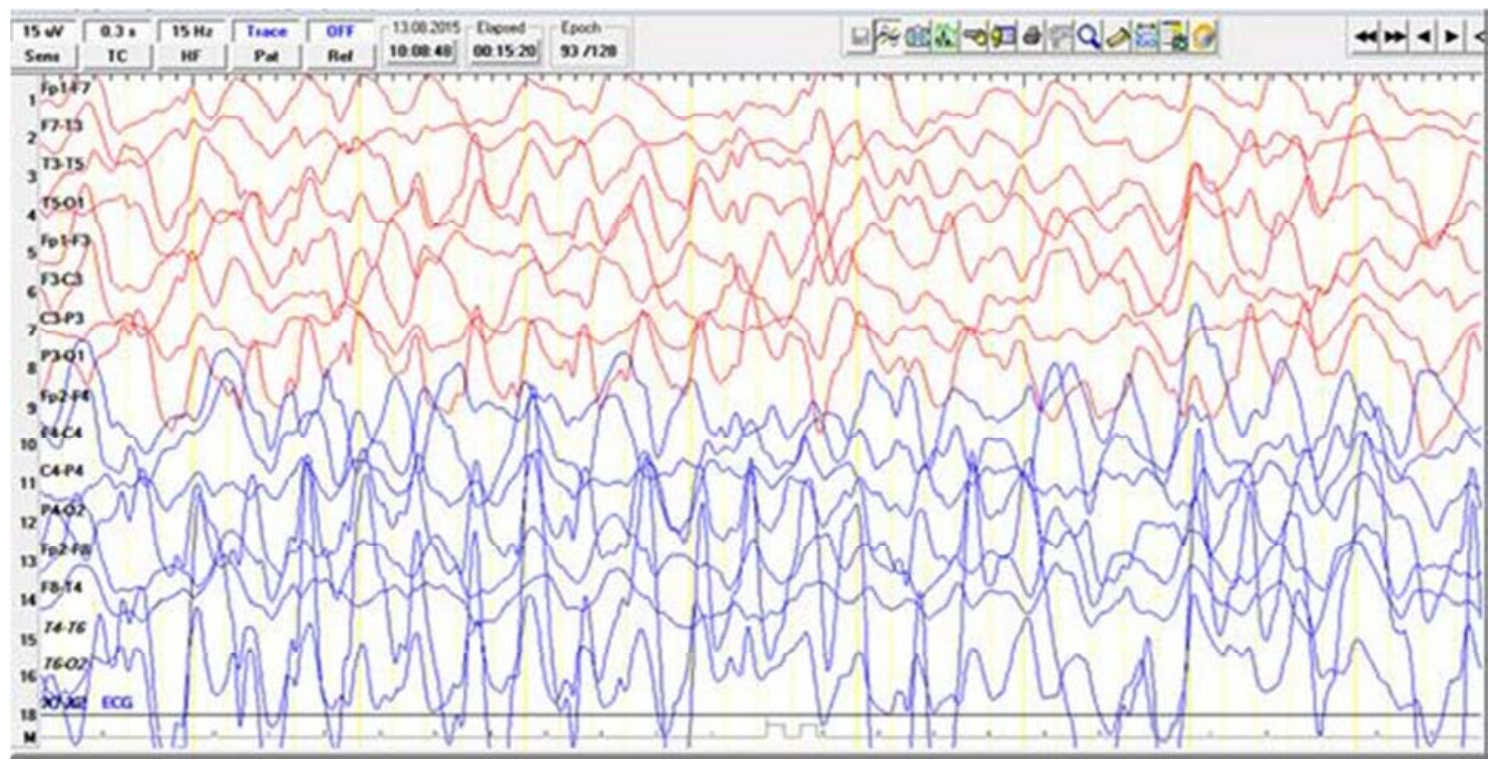

Figure 3. 9 year-old girl with Angelman syndrome. Right hemispheric occipital discharges and nothched delta pattern. 


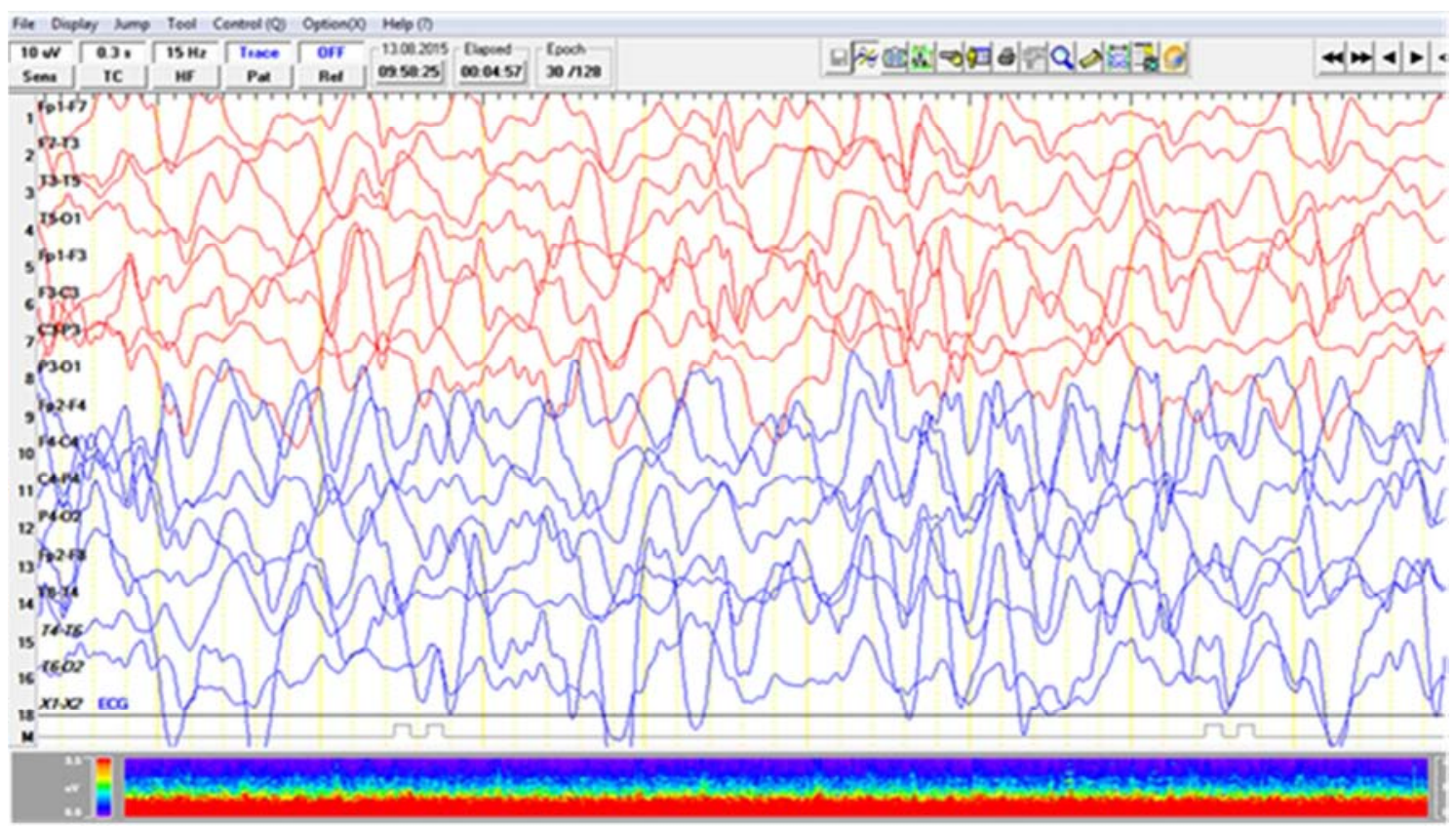

Figure 4. Z. D. Ç, 9 year-old-girl, Angelman (same patient above). Notched delta pattern was shown.

Prader Willi Syndrome (PWS) might be because of a deletion of a 5 to $6 \mathrm{Mb}$ region from the paternally contributed chromosome $15(65-75 \%)$, by maternal uniparental disomy (UPD; $20-30 \%$ ), or by a defect in the genomic region that controls the imprinting process (imprinting centre defect; 1 $3 \%$ ).

Patients with PWS have typical physical characteristics as well as behavioural, neurological, and endocrinological abnormalities. In the PWS patients, the prevalence of epilepsy is $4 \%$ or $22 \%$, it is significantly lower than the $85 \%$ reported among those with Angelman syndrome. Epilepsy has been reported, both generalized and focal. It is obserded in the deletion group than among patients with either UPD or an imprinting centre defect, yet the correlation between genetic subtype and the risk for epilepsy have not been clerified. Our 5 PWS patients had chromosomal deletion and of 3 them have focal 2 have generalized seizures. Long-term follow-up of these patients in terms of epilepsy has shown that those with structural brain lesions have a worse prognosis [8].

Ring chromosome 20 is a rare chromosomal anomaly characterized by drug resistant epileptic seizures, behavioral disorders and mental retardation. Phenotypic features include features such as microcephaly, hypertelorism, high arched palate, hypogenitalism, and low set ears, but not as obvious as other syndromes [2]. Mental retardation is often seen, but there are also publications that indicate normal [9]. Seizures often start between the ages of 1 to 14. Seizures are usually tonic seizures that can interfere with sleep terror, similar to the semiology of frontal lobe seizures. In addition, generalized tonic clonic seizures, diving seizures and seizures leading to visual symptoms are common [10].

The diagnosis age was reported as 5.4 years in a metaanalysis study. The reason of delayed diagnosis in these patients is that the dysmorphic features are faint and the only symptom is epileptic seizures. At the onset of seizures, the EEG may be normal, but pathologic findings settle over time [11]. Pathological findings can be listed as follows;

1. Frontocentral dominant transient teta wave sequences on normal background rhythm

2. High-amplitude slow waves with rare frontal sharps in the state of nonconvulsive status epilepticus [4].

There was only one patient with ring chromosome 20 anomaly in our study. The patient had mild mental retardation and hyperactivity besides minimal dysmorphic features. In this patient's EEG, sharp wave activity in the frontal regions was indicating focal activity. Seizures remained resistant despite the appropriate dose and duration of conventional antiepileptic drugs and the patient was admitted to the vagus nerve stimulation (VNS). It has been observed that seizures are reduced by more than $50 \%$ with VNS. In the literature, there is Ring 20 cases benefit or not benefit from VNS $[12,13]$.

Rett syndrome is seen almost exclusively in females and caused by the mutations in the X-linked gene $\mathrm{MeCp} 2$ (Methyl-CpG-Binding Protein 2). MeCp2 (methyl-CpGbinding protein 2) is responsible for gene transcription and plasticity in neurons [15]. Affected individuals are often normal at birth and during the first 6 months after birth, then the language, fine skill and cognition remission seen. Stopping of the increase in head circumference and sterotypical hand movements are typical features. Walking and movement disorders, respiratory problems are common. Seizures are present in $70-90 \%$ of patients [16]. As well as high voltage delta frequency slow waves it is characterized with multifocal short-spine slow wave activity which is more obvious in central regions in EEG. However, as mentioned in the studies and metaanalyses, the EEG pattern in Rett syndrome shows a wide spectrum ranging from sleep-wake slow wave pattern and multifocal activity to normal sleep 
activity.

In a study conducted by Kim et al. [1] on 20 Rett syndrome patients in Korea, it was reported that 14 patients have epileptic seizures and only one patient's EEG was normal.

In a review of conducted by Dolce et al. [17], it has been reported that there are 4 different EEG findings in the 4 stages of Rett syndrome. EEG may be normal or occipital slow background rhythm in stage 1 . The $2^{\text {nd }}$ phase shows "rapid destructive phase" of the disease and sharp wave activities began to seen in the frontocentral region. In the $3 \mathrm{rd}$ phase known as "the plateau phase" as well as started to slow down of background rhythm completely and rhythmic teta waves and multifocal epileptic disorder appears. In the $4^{\text {th }}$ final stage the epileptic activities seen in the $3^{\text {rd }}$ stage settled completely and background rhythm was disorganized along the entire trace.

There were a total of 7 Rett syndrome patients in our study. Of these, 3 were in the $3^{\text {rd }}$ phase of the disease and 4 were in the $4^{\text {th }}$ phase. Typical EEG findings of our patients are shown in Figures 5 and 6.

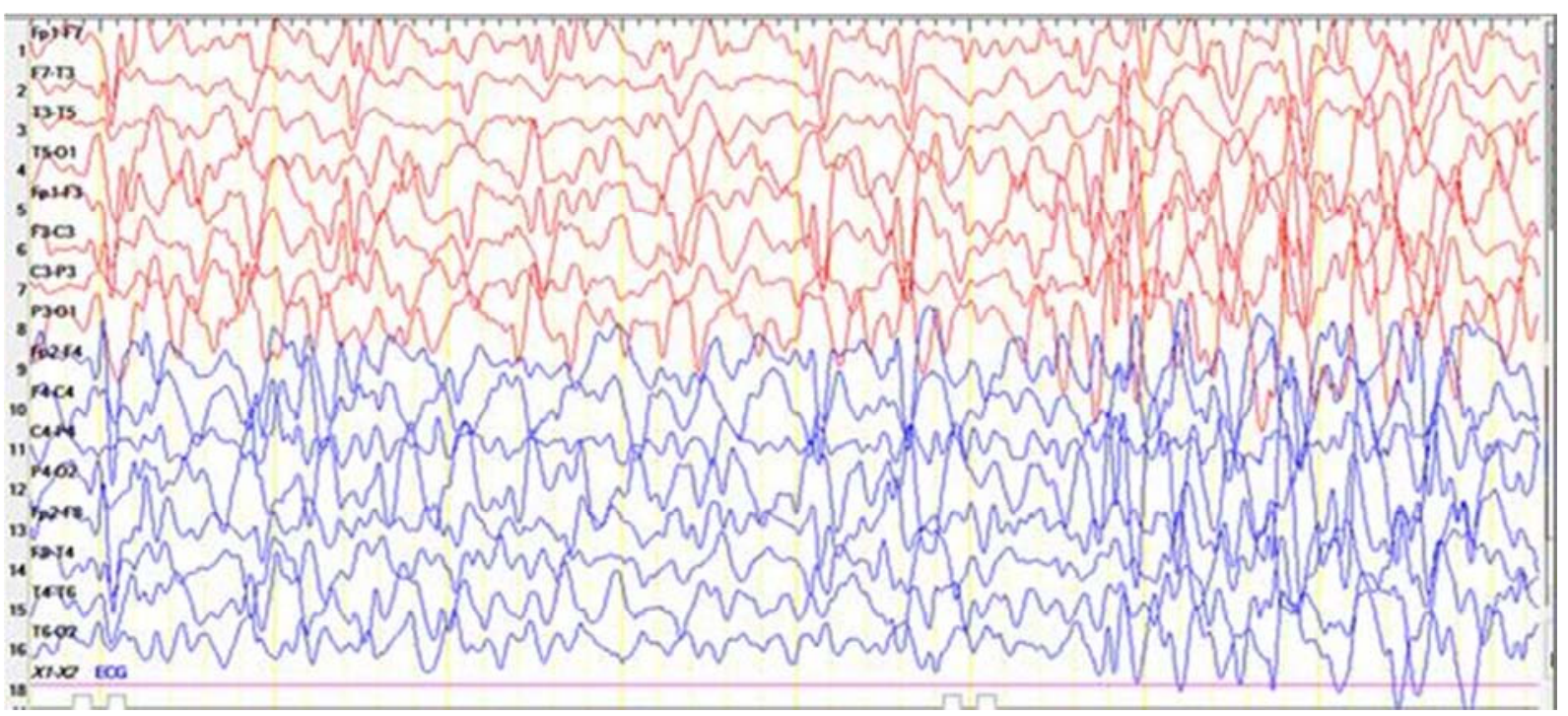

Figure 5. 4 year-old girl with Rett syndrome in $3^{\text {rd }}$ stage. EEG pattern shows rhythmic generalized spike wave activity.

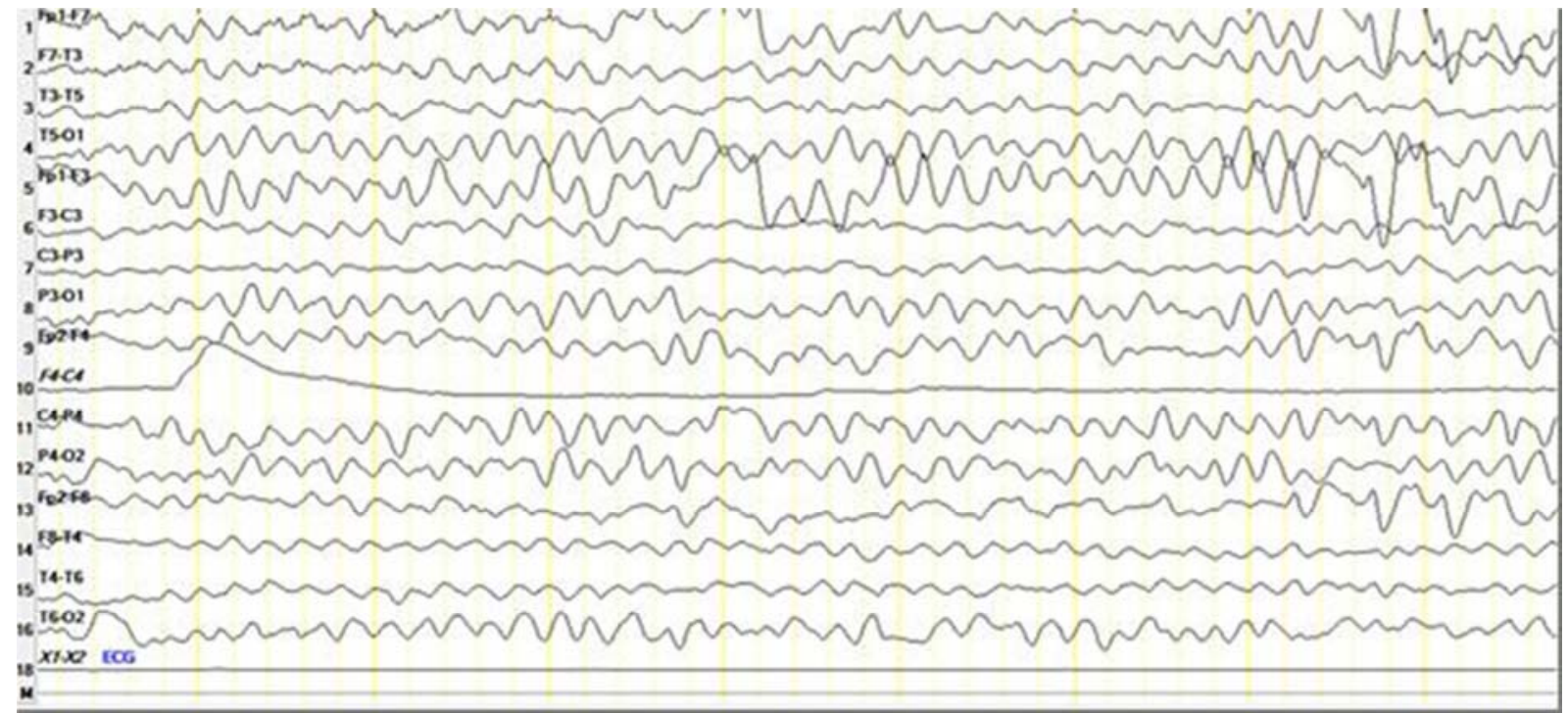

Figure 6. 8 year-old girl with Rett syndrome in 4rdstage. Slow teta rhythm is shown in the EEG sample.

In addition to genetic syndromes with more limited patterns of seizure and EEG patterns, epilepsy is also accompanied to many genetic syndromes such as Down syndrome, Frajil-X syndrome, Wolf-Hirschhorn syndrome, Miller Dieker syndrome, 18q-syndrome, but EEG and the seizure patterns specific to these diseases are not defined [14]. Since the mentioned syndromes seen fewer in our study, typical EEG patterns could not be detected.
Chromosomal anomalies like Down syndrome and Patau syndrome are characterized by gross dysmorphic features and are more common than the other genetic-dysmorphic syndromes. For this reason, the mean age of diagnosis of this group of patients was statistically significantly lower than the others $(\mathrm{p}=0.034)$.

Only 30 of the patients could be tested for WISC-R. According to this test, the patients were divided into 3 groups 
as mild, moderate and severe mental retardation (MR). WISC-R test was applied to 6 patients in chromosomal anomalies, 1 of them $(16.3 \%)$ had a middle MR and 5 of them $(83.7 \%)$ were severe MR. Severe MR ratio was detected as $46.2 \%(\mathrm{n}=6)$ in microdeletion-duplication syndromes and $45.5 \%(n=5)$ in monogenic syndromes. The high rate of severe mental retardation in children with chromosomal abnormalities was accepted as statistically significant $(p=0.032)$. Central nervous system anomalies are accompanied in many genetic syndromes. Structural and sequel lesions were found to be higher in patients with chromosomal anomaly than the others and it was accepted as statistically significant $(p=0.42)$. In a similar study, 74 patients with genetic dysmorphic syndrome were evaluated and $70 \%$ had central nervous system and/or sequel lesions [18]. This rate was found as $30 \%$ in our patient group. This difference may be due to the inadequacy of the patient group or the presence of patients diagnosed only with clinical findings that have not been confirmed by genetic testing.

Seven of the patients included in our study were Down syndrome. Of these patients, 5 had sequel cerebral lesions and 2 of them had normal MRI. While the seizure type of one patient with normal MRI was infantile spasm type, the others had focal and secondary generalized seizures. Two patients with Down syndrome who had cerebral lesions had cardiac surgery, 2 had hypoglycemia and 1 had asphyxia history. Yamanouchi et al. [20] evaluated 128 patients, who were admitted to neonatal intensive care unit, detected chromosomal anomaly. They reported that 71 of 128 patients had Down syndrome, and 5 of them had epileptic seizures. One patient underwent Lennox Gastaut syndrome and moderate cerebral atrophy was found in the MRI. In the other four patients, hypoxic ischemic sequel and Moya-Moya disease were detected. In another study, 104 patients with Down syndrome who had cryptogenic seizures were evaluated and the type of $51(49 \%)$ of them determined as infantile spasm pattern [19]. The seizure type of the only one patient with cryptogenic seizure in our study was infantile spasm.

Our only patient with cryptogenic ethiology had infantile spasms. It is stated in the literature that patients with Down syndrome often have seizures due to secondary causes, which will be on the same line as our study.

Although the observation that 7 of 50 patients' EEG is encephalopatic was not statistically significant $(p=0,196)$, the importance of EEG in the early identification of encephalopathies in patients with genetic disorders is undeniable.

\section{Conclusion}

This study was designed to identify specific EEG and seizure patterns in specific genetic syndromes and to provide source for large-scale metaanalytic studies to be conducted in later periods. Learning of the typical EEG patterns of Angelman and Rett syndrome may lead to earlier diagnosis and earlier treatment initiation. The karyotype investigation or genetic screening of patients with epilepsy in the infantile period who have dysmorphic features or developmental delay may facilitate the diagnosis on the path of diagnosis.

\section{References}

[1] Kim HJ, Kim SH, Kim HD et al. Genetic and Epileptic Features in Rett Syndrome. Yonsei Med J 2012; 53: 495-500.

[2] Garcia DM, Ortiz R, Gomez A, Barriuso E. Ring 20 chromosome syndrome Epilepsy with Dysmorphic features: A Case Report. Epilepsia 2001; 42: 1607-1610.

[3] Buiting, K, Williams C, \& Horsthemke B. Angelman syndrome - insights into a rare neurogenetic disorder. Nat Rev Neurol. 2016 Oct; 12 (10):584-93.

[4] Sorge and Sorge, Epilepsy and chromosomal abnormalities. Ital J Pediatr 2010; 3: 36.

[5] PJ Wang, JW Hou, WC Sue, WT Lee. Electroclinical characteristics of seizures - comparing Prader-Willi syndrome with Angelman syndrome. Brain Dev 2005; 4: 101-107.

[6] MS Yum, EH Lee, JH Kim, TS Ko, HW Yoo. Implications of slow waves and shifting epileptiform discharges in Angelman syndrome. Brain Dev 2013; 35: 245-251.

[7] Bakke, KA, Howlin, P, Retterstøl L, Kanavin ØJ, Heiberg A, Nærland T. Effect of epilepsy on autism symptoms in Angelman syndrome. Molecular autism, 2018:9 (1), 2.

[8] Verrotti, A, Cusmai R, Laino D, Falsaperla R, Margari L, Rizzo R et al. Long-term outcome of epilepsy in patients with Prader-Willi syndrome. Journal of neurology, 2015:262 (1), 116-123.

[9] Ville D, Kaminska A, Bahi-Buisson N et. al. Early pattern of epilepsy in the ring chromosome 20 syndrome. Epilepsia 2006; 47: 543-549.

[10] Vignoli A, Bisulli F, Darra F, Mastrangelo M, Barba C, Giordano L et al. Epilepsy in ring chromosome 20 syndrome. Epilepsy research, 2016:128, 83-93.

[11] Yip MY. Autosomal ring chromosomes in human genetic disorders. Translational pediatrics, 2015:4 (2), 164.

[12] Alpman A, Serdaroglu G, Cogulu O et. al. Ring chromosome 20 syndrome with intractable epilepsy. Dev Med Child Neurol 2005; 47: 343-346.

[13] Chawla J, Sucholeiki R, Jones C, Silver K. Intractable epilepsy with ring chromosome 20 syndrome treated with vagal nerve stimulation: case report and review of the literature. J Child Neurol 2002; 17: 778-780.

[14] Agatino Battaglia, Renzo Guerrini. Chromosomal disorders associated with epilepsy. Epileptic Disord 2005; 7: 181-192.

[15] Amir RE, Van den Veyver IB, Wan M, Tran CQ, Francke U, Zoghbi HY. Rett syndrome is caused by mutations in X-linked MECP2, encoding methyl-CpG-binding protein 2. Nat Genet 1999; 23: 185-188.

[16] Neul JL, Kaufmann WE, Glaze DG, Christodoulou J, Clarke AJ, Bahi-Buisson N, et al. Rett syndrome: revised diagnostic criteria and nomenclature. Ann. Neurol. 2010:68, 944-950. 
[17] Dolce A, Ben-Zeev B, Naidu S, Kossoff EH. Rett syndrome and epilepsy: an update for child neurologists. Pediatr Neurol $2013 ; 48: 337-345$.

[18] Alfei E, Raviglione F, Franceschetti S et. al. Seizures and EEG features in 74 patients with genetic-dysmorphic syndromes. Am J Med Genet Part A 2014; 164A:3154-3161.
[19] Verrotti A, Cusmai R, Nicita F et. al. Electroclinical features and long-term outcome of cryptogenic epilepsy in children with Down syndrome. Pediatr 2013; 163: 1754-1758.

[20] Yamanouchi H, Imataka G, Nakagawa E et. al. An analysis of epilepsy with chromosomal abnormalities. Brain Dev 2005; 27: 370-377. 